\title{
We Have to Rewrite Psychology and Psychiatry
}

\author{
Dr. Philip Dammen
}

\begin{abstract}
Psychology and psychiatry are facing unresolved scientific challenges: We still do not know how the experience of psychological $(1,2)$ disease is constructed mentally, and what happens mentally when the patients is experiencing a change in treatment, when in the consultation there is a psychological change, and what type of psychological material that can prevent mental change. Diagnoses, as presented in the international diagnostic systems ICD 11 (3) and DSM IV (4) are not sufficiently valid in the sense that they are not precise, controllable expressions of the mental experience of mental torment. Neuro psychology (5) lacks an adequate understanding of the importance of their findings when it comes to understand the psychological and mental processes leading to psychological torment. Moreover, we still do not have a sufficiently scientifically approach to treatment, diagnosing and research on mental illnesses (1, $30,31,7)$. We must rewrite psychology and psychiatry before these subjects will appear to be sufficiently scientific. This article will elaborate on some challenges related to psychology and psychiatry, neuro-psychology and problems that the diagnostic systems ICD 11 and DSM IV are facing.. At the end, the article will describe some solutions to this situation.
\end{abstract}

ONE MUST DISTINGUISH BETWEEN THE INNER AND OUTER EMPIRICISM.

To develop a scientific knowledge on mental disorders, psychology and psychiatry must expand their focus from external observations (8) and narratives $(9,10,11,12)$ to a focus on the inner mental experiences. One must therefore distinguish between the outer and inner empiricism. The inner empiricism is defined as the individual's inner experience of mental torment. While the outer empiricism is understood as observations of behavior, statements, and emotional responses that are interpreted as expressions and information about the mental disorder. The outer empiricism also contains information about the situations and events that the mental torment has taken place within. While the inner empiricism consists of the mental elements which support and are the basis for the mental torment.

Studies of the outer empiricism and of the external observations will not lead to objective knowledge about the mental disorders, but only to intersubjective consensus among researchers and therapists about what is perceived as true and objectively about mental disorders. The intersubjective consensus among researchers $(30,13)$ and between psychologists are not objective, but must be looked upon as a collective therapist- and researcher subjective knowledge about mental phenomena. Knowledge of mental disorders based on the outer empiricism will therefore contain systematic errors with respect to validity.

The type of empiricism that dominates the positivistic $(14,15)$ and natural science acts as a barrier against research on mental states and emotions. This is because no behavior, no thoughts understood as information and no interpretations of the patient's psychological torment (16) are the patient's feelings, or the mental disease as a mental experience.

\section{A prerequisite for developing scientific knowledge of mental disorder}

Valid knowledge about mental health conditions and ailments can only be developed when it is based on how the client feels and senses the psychological torment. Both natural science and 
the qualitative approach to research on mental disorders $(17,18)$, and the therapeutic traditions must therefore increase their focus on the inner empiricism and reduce their preoccupation with the outer empiricism. Today we are using sufficiently scientific methods and procedures $(14,15,19,21)$ but on outer empiricism, i.e. on quasi-scientific objects for emotions, mental states and the mental disorders. Our research objects do not satisfy the claims to be a scientific researchable psychological object.

\section{We must distinguish between mental and somatic disorders}

To develop scientific knowledge of mental health problems, one must distinguish between mental and somatic anchored psychological distress. Mental anchored ailments are defined as ailments that can be influenced and changed through verbal therapy, i.e. through language. While somatic rooted psychological, problems are defined by not being sufficiently changeable through language

A mental biological phenomenon anchors the mental states and the mental disorders

There is a mental phenomenon or a mental biological condition that anchors emotions, mental states and the experience of mental anchored diseases (1,2, ) This mental biological phenomenon is involved in all mental processes and in all psychological changes. This phenomenon is named the bio-psychological units because this phenomenon is both consisting of psyche and biology.

In the moment we have access to this mental phenomenon; we have an approach to the patient's experience of mental pain, as long as the mental pain has a psychological and not a biological basis. These mental elements, the bio-psychological units are the building blocks of the psyche. They form the basis for developing the emotional state. They anchor the smallest and most limited feeling, but also the most complex mental state and mental disease. They consist of an emotional element, a biological element, a modal element and often, but not always, of a linguistic element. These sub-elements constitute a mental unit. They are interdependent in the sense that if you change one element in the bio-psychological entity that holds an emotion, you also get a change in the other sub elements within this mental biological entity $(1,2,3)$.

This situation can be illustrated through redefinitions (2, 23) i.e., through a widespread therapeutic intervention. Redefinitions are leading to a change in the patient's emotions by changing the words through which the patients are understanding and emotionally experiencing the psychological disease. Words have meaning, but words are also sounds and hence auditory sensations. Redefinitions thus lead to another mental focus, and then to other emotions, which in turn reflects a new neurobiological state of the brain. Any intervention that works follows this pattern, even if the chronology will be different. This situation means that the one can change feelings by changing the modal and linguistic elements that support these feelings (24).

These mental elements contain the properties needed to examine the mental torment and to build a positive mental state and a new response pattern in patients. They are observable through introspection and thus documentable for the client and for the therapist through the patient's language. They might be divided into smaller elements with the result that we accurately can identify the psychological material that triggers the psychological distress. And map the bio-psychological elements that maintain the mental processes leading to mental 
torment. These mental elements can be stable, as in phobias and traumas, and in this way be the basis for the stability of the psychological torment. However, they are also changeable, and in this way the basis for the individual's ability to change through daily experiences and treatment.

These elements are produced through mentally processes, and throughout treatment with the result that there is an ongoing creation of a new psychological reality for the patients. These elements may be transformed, in the sense that if an emotion stored at a particular modal or linguistic element, that is less alterable for therapist, can be transformed to and experienced through another modal or linguistic element that is more alterable, without changing the emotional intensity. For example, an experience of free-floating anxiety that is less alterable can be transformed through therapy to a more alterable modal element - with the result that the therapist may reduce or get rid of the mental pain. This possibility is vitally important to get positive results in therapy.

It is important that the therapist is aware of the characteristics contained in the biopsychological elements, and the importance of these mental elements for the development and the emotional experience of mental torment. If not, the therapist may become blind to the patients resources for mental change.

\section{The psychological problems are simple phenomena}

We can perceive the psychological problems and behaviors and the mental disorders as complex and incomprehensible. Nevertheless, they are simple mental constructions. The immediate experience of mental torment is a result of access to some specific mental elements (see above) that hold the feelings associated with mental pain. The persistent mental torment is therefore, logically seen, caused by a persistent access to mental elements that accommodate mental pain. Research results suggest that the mental processes that trigger the mental torment is maintained by access to mental elements that accommodate mental discomfort (12). The mental patterns that trigger and maintain the mental pain may be modified by changing these mental elements (24). This means that we can change habitual unpleasant mental reactions without focusing on information's about the circumstances in which the mental torment unfolds, and without focusing on patients' stories. $(1,2)$.

\section{There are only one mental disorder with variations}

Another consequence that is mentioned previously is that there are no fundamental differences in the mental biological structure of the normal mental state and the immediate experience of the mental anchored pain, although the emotional discomfort and the behavior of the patients are different in the different mental states. Both these conditions are a result of contact with the bio-psychological elements and they are modified in the same way, through a change of the mental elements that store the emotions associated with these conditions. The similarities between the mental anchored disorder and the normal mental state are therefore more important for understanding these mental states than the differences between them.

On this basis, one can argue that there is only one psychological anchored disorder, and that all mental ailments are variations of the normal mental state. The diagnostic systems ICD 11 and DSM IV that tells that there are around 400 different mental disorders $(3,4)$ is not correct . These figures are based on studies of the outer differences between mental disorders that do not reflect the mental biological similarities between how the different mental disorders are mentally experienced. The number of alleged mental illnesses of about 400 as outlined in the diagnostic systems ICD 11 and DSM IV, which is a result of a focus on outer empiricism, is thus 
not objective and true. It goes against the general logic to operate with this number when we can treat the mental anchored disorders the same way.

There are still differences in the emotional experiences between mental torment and mental well-being. We can map these differences by observe the differences between the modal and linguistic elements that the patients have access to.

\section{The mental states are observable}

The patients can observe their mental states through introspection - by the therapist and researcher through the patient's words about the mental pain. The therapist can then observe the relationship between the patient's language and the experience of mental torment. By this one can accurately identify the mental processes that lead to mental illness, and what happens pure mentally when there is a change because of treatment, just by identifying changes in the mental elements connected to certain situations before and after each intervention or a consultation.

\section{The intersection between biology and psyche.}

When this is possible (above), we have established the basis for developing a scientifically sound and researchable approach to the treat the mentally anchored disorders. In this we have also mapped the spot where the mental states are transformed from conscious to unconscious biological material, and the spot where mental biology, the unconscious material, turns into conscious psyche, which is a spot still not discovered by science. Understanding this spot we do have a vast potential for further development of the neuropsychology and for understanding the link between the conscious and unconscious states, and between biology and psyche. This neurobiological spot I have called the intersection between biology and psyche. For understanding this spot, we have to focus on the emotional part in the modal and linguistic elements.

\section{Mental changes and mental processes are following the same pattern}

Just as there is no fundamental difference in the structure of the mental torment and normal mental states, even though the emotions are perceived differently, there is no fundamental difference in the mental processes that lead to changes in everyday life and the psychological changes that occur as a result of treatment. In addition, there is no principal differences between the mental processes leading to mental disorders and mental wellbeing. The different mental processes are all predictable and observable by observing the mental elements that are connected to these different mental states. The differences though is that the changes through therapy, coaching or self-help procedures will be a result of thoughts and language, while changes in daily life will be a result of the inner voice and the various inner modal sensations.

This situation makes it possible to identify what is happening mentally with patiens when there is a change through treatment by observing the process of coupling and decoupling of mental elements that hold the mental discomfort $(1,2)$. This will apply to all verbal therapeutic traditions and it is independent of the method that is used. It is also possible to identify when in the consultation there is a mental change, and whether and why the patients sometimes does not obtain a mental change in treatment. It will also be possible to identify the mental biological elements that prevent patients from changing mentally. In addition, it will be possible to identify what remains of psychological distress by mapping the remaining mental elements, which still hold mental pain (1). 


\section{About the simplicity of treatment and some prerequisites}

In most cases, it is easier to treat mentally anchored problems than the psychiatry and psychology assume (25). Mental changes because of therapy may be as fast as the psychological changes that happen in the daily life and sometimes much faster. The pace of change will be a result of the patients' personal characteristics, the therapist's work method and his or her way of using language, and the patients' relationship with the therapist $(19,20)$.

One of the prerequisites for mental change in therapy is that the patient has a good relationship with the therapist and treatment. Another is that the patient has access to the psychic material that is to be changed and to the mental resources needed in making the emotional change. If patients do not have access to the psychic material that triggers the mental pain, it is possible to give the patient access to this material in the treatment situation. A third condition for mental changes in therapy is that the patients are intellectually accessible, motivated for mental change (19), and that the psychological change is not hindered by somatic illness or injury, or by side effects of medications. One more prerequisite for mental changes is that you give the patients greater access to the mental elements that accommodate increased coping skills and increased psychological well-being and that one reduce the connection to psychic material that holds the mental pain.

\section{All therapeutic traditions gets results}

However, as mentioned above, all therapeutic traditions do get results $(19,20)$. Why? Because every verbal therapeutic tradition are changing the mental elements that constitute the immediate mental pain when therapy works for the patient. This occurs even if the therapists are not aware of this fact. However, since the therapists and the researchers are not aware of to which extent they are dealing with these mental elements, they will base their interventions on their pre-understanding more than on the mental elements that control the patient's immediate emotions. This opens for therapeutic failures, failures that will happen without the therapists understanding of what is going on, and about what is preventing the mental improvement for a certain patient, although the therapist earlier have had good results with other patients after having used the same methods.

These claims are not in contrast to the fact that the clients often do get results in therapy (19, $20,26,33)$. Good results in therapy are telling that it is possible to get results in therapeutic traditions even if they do not have a sufficient scientifically basis $(1,2)$. People have helped each other for thousands of years without knowing exactly what they were doing. However, scientifically knowledge is important when therapist do not get the expected results in therapy, and when one need to research the psyche and the mental processes, and when we are trying to diagnose the mental disorder. The situation today is that psychology and psychiatry are producing a vast amount of not valid knowledge about the mental disorders.

One conclusion is that to develop a sufficient scientific treatment the therapists and researchers, to some extent, must abandon their focus on interpretations, and focus precisely on words that illustrate how the patient experiences the mental disorder. Every verbal treatment must have the patient's word as basis for attention if we want to work scientifically accurate with the mental torment.

\section{The results from Meta research on what works in therapy, not sufficiently valid}

This claims (above) stand against some results in the Meta research claiming that methods only count for around $15 \%$ of the treatment results (19). This conclusion contains systematic errors with respect to validity. The arguments are as follows. 
1. It is impossible to measure the importance of therapeutic method if the researchers do not have a sufficiently scientific knowledge of how the mental disorders are constructed mentally. In addition, this is the case: The researchers have focused on quasi objects for the mental disorders, i.e. objects that are not valid expression for the mental disorder or mental change as in inner experiences.

2. Even if the researchers have not found differences between therapeutic traditions concerning results in therapy, one cannot draw a conclusion that methods do not count. What is found by examining some methods and research findings, cannot predict what might be. They cannot exclude the existence of methods that are more effective in reducing the mental disorder than the methods or traditions examined.

3. To measure the outcome of therapeutic methods, we have to examine the mental changes in a certain moment in the therapeutic consultation, i.e before and after a certain intervention on a certain mental problem. If the researchers have not been able to do this kind of examination, the conclusions are reduced from science to interpretations. This is the case for the Meta research

4. It is true that patient-related factors are important for what can be achieved in therapy, and that the relationship between therapist and client is crucial for the results $(19,20$, 26). Although a good relationship between the therapist and the client alone is not sufficient for good results in therapy. However, the ability to establish a good relation, and to apply and activate the client's mental resources in the therapeutic process is not all therapists granted. All what the therapists are doing in the consultation are methods. A good relation between the patients and the therapists are then a result of a methodological approach, and then should be understood as a method.

5. The less the therapist is able to measure the psychological changes, the more difficult it becomes to measure the effectiveness of the methods employed, and vice versa. The faster you achieve mental change, the easier it will be to determine the importance of the methods for the therapeutic change.

6. The conclusion is that Meta research neither have a sufficiently valid understanding of the mental disorder and of mental change, and about what is a therapeutic method. The results of the Meta research (27) are still important, but have to be examined more thoroughly before they should be fully accepted.

\section{Neuropsychological challenges}

Another challenge when trying to develop a predictable and controllable treatment of mental disorders stems from neuropsychology and neuroscience. Neurobiology and neuroscience encourages optimism about what can be achieved through neuropsychological research. In addition, neuro-psychology is characterized by perceptions that, in the near future, it will be possible to cure mental disorders through medical interventions and through psychotropic drugs (28). Nevertheless, before reaching this aims they have to answer one crucial question: What is the direct link between the neurobiological findings and emotions and the mental experience of the mental disorder. This challenge will not be solved before neuropsychology does have a sufficient scientifically understanding of the mental disorder and the psyche. It is however possible to map the relationship between biological and mental processes, and detect how we can measure biological changes in the brain because of verbal therapy, without brain scanning techniques. It is also possible to identify the limits of various methods for brain scanning when it comes to measure changes in the brain because of therapy. This can be done even without brain scanning. These possibilities presuppose an understanding of how emotions are constructed mentally, and how we can control mental changes through therapy. 
Neuropsychology and neuroscience lacks this knowledge and thus the ability to interpret accurately the neurobiological research findings $(5,6)$

A study of 17 of the most famous family and individual therapy traditions showed that none had developed knowledge of the mental biological foundation of mental problems and disorders (1) Despite this situation, it is possible to develop a therapeutic design that can be used to examine the relationship between neurobiological and psychological conditions. The solution lies in the possibility of mapping the emotions and the mental elements that constitute the mental disorder, change these elements through treatment, and then map the emotional change and changes in the mental elements after the interventions. Only after a correct understanding of mental processes and of how psychological distress is constructed, we fully will understand the findings presented through brain research (1). The same challenges that neuro psychology is facing is found in the field of diagnostics.

\section{Diagnostic challenges}

Diagnoses in ICD11 (3) and DSM IV (29) are not sufficiently scientific as expressions of mental disorders, because they do not represent precise and verifiable knowledge of the psychological distress as a mental experience. No diagnoses will be valid if they do not describe precisely the patient's emotional and sensational experiences of the mental pain. Diagnoses in ICD 11 and DSM IV are therefore characterized by systematic errors with respect to validity. One explanation of this assertion is that those who have developed the diagnostic systems do not have an adequate scientifically grounded understanding of how the various mental ailments are mentally constructed. And they do not know what happens mentally when there is a change through treatment. Another explanation is that the diagnostic systems primarily are based on outer empiricism.

Neither behavior and thoughts nor observations of emotional reactions are sufficient to diagnose the emotional basis for the mental disorders. In addition we have to be aware of that diagnoses in ICD 11and DSM IV are a result of decisions on international medical congresses, where topics such as the importance of the modal and linguistic elements for the mental disorders are given little or no attention (2).

Psychiatry and psychology need a new diagnostic system, or a system that extends and modifies the existing ones. The development of new or expanded diagnostic system must be based on how the mental suffering is experienced through the inner sensations and modal experiences and the language of the patient. The development of the nano psychological diagnostic system, here named NADIS, can be an alternative because it is based on characteristics of mental elements that are focused in this article, and with the same theoretical understanding as background. The nano diagnostic system will be fully developed in the 2015.

\section{FINAL WORDS}

This article has outlined some of the challenges of the scientific psychiatry and psychology, to some scientific limitations connected to interpretations, and on the defects of the hermeneutic approach to understand the mental disorders. The article has also mentioned some faults concerning the international diagnostic systems.

Despite the fact that the individual and family therapy traditions get results, none of these traditions have given precise answers to the challenges described in the introduction of this article. The different treatment traditions are therefore based on, and produce knowledge about mental problems and changes that only is partially correct. What is lacking is a scientific 
qualitative grounded knowledge about how the mental disorder are constructed as a mental biological phenomenon and about what happens mentally when there is a mental change because of treatment. What is lacking is the basis for the development of an adequate scientific controllable psychology and a sufficiently scientific, predictable and controllable approach to the treatment of psychological problems. The conclusion is that parts of psychology and psychiatry have to be rewritten, and that it must be designed a new psychology based on surveys of mental elements that constitute the patients' experience of mental torment. The solutions are to change the psychological focus from external observations to the client's inner experience of the mental agony, and to focus on the mental elements which is the basis forth mental torment. Only then it will be possible to develop a scientifically valid knowledge about the mental disorder as a mental phenomenon and about what happens mentally when patients are getting better through treatment, only then can we examine what is missing when we do not get the assumed results in therapy.

The purpose of this article is to address some limitations with respect to validity in the scientific knowledge about mental disorders. The second is to point on some solutions that would make psychology and psychiatry more sufficiently scientific based subjects. The third intention is to encourage the optimism about the possibility of developing a predictable and controllable therapy that can help people with mental problems and mental anchored disorders faster, with better average results and with less costs than to today. One of the answers are lying in the developing of Nano psychology and Nano therapy, an approach to psychology, treatment, diagnostics and research that will be published later in 2015 .

\section{ACKNOWLEDGEMENTS}

My thanks is to Anne-Grethe Tuseth who introduced me to the field of family therapy, to Barry Duncan for inspiring talks about what works in therapy, in an important period of my work. My thanks also go to inspiring and awakening lessons with Michael White, David Epston, Kenneth Gergen, Harlene Anderson and Steve deShazer. Important intellectuals that also have inspired my rethinking of parts in psychology and therapy are Richard Bandler and John Grinder presented with clarity and enthusiasm from Truls Fleiner og Jorunn Sjøbakken. My thanks also go to Edvard Befring, a norwegian professor and personality when it comes to quantitative research end ethics, who encouraged my work in a period still characterized by uncertainty.

\section{References}

1. Dammen Ph. En undersøkelse av psykisk plage og psykisk endring med utgangspunkt i enkelte endringsprosesser. (A study of psychological distress and mental change as a result of treatment. Akademika forlag: Oslo. Norway, 2013.

2. Dammen Ph. Logic, Psyche and Biology. Psychology and Behavioral Sciences. Vol. 2, No. 3, 2013, pp. 106111. doi: $10.11648 /$ j.pbs.20130203.14

3. Helsedirektoratet. ICD-10: den internasjonale statistiske klassifikasjon av sykdommer og beslektede helseproblemer : systematisk del, alfabetisk indeks (forenklet). Helsedirektoratet. Oslo. Norway, 2011.

4. APA. Diagnostic and Statistical Manual of Mental Disorders: DSM-IV. American Psychiatric Association: US, 2011.

5. Gazzaniga, M. S., Ivry, R. B., \& Mangun, G. R. Cognitive Neuroscience, Second Edition. W. W. Norton \& Company, 2002.

6. Damasio A. Descartes' feiltagelse: fornuft, følelser og menneskehjernen. Pa(x: Oslo, Norway, 2004. Translated from: Descartes' Error. Emotion, Reason, and the Human Brain. Amazon, NY, USA, 2000. 
7. Hawton, K., Salkovskis, P. M., Kirk, J., \& Clark, D. M. Cognitive Behaviour Therapy for Psychiatric Problems: A Practical Guide. OUP O(xford, 1989.

8. White, M. Selected Papers. Adelaide: Dulwich Centre Publications, 1989.

9. White, M., \& Epston, D. Narrative Means to Therapeutic Ends (1. utg.). W. W. Norton \& Company, 1990.

10. Lundby, G. Narrativ terapi. København: Hans Reitzel. 2006.

11. White, M., \& Epston, D. Re-Authering Lives. Interviews \& Essays. Adelaide: Dulwich Centre Publications, 1995.

12. Watzlawick, P., Weakland, J. H., \& Fisch, R. Forandring: Prinsipper fra psykoterapien. Gyldendal. Oslo. Norway, 1980.

13. Svartdal, E. Forskingsmetode med etikk og statistikk. Samlaget,. Oslo. Norway, 2007.

14. Svartdal, F. Psykologiens forskningsmetoder. Fagbokforl. Bergen,. Norway 2009.

15. Vetlesen AJ Stânicke E. Fra hermeneutikk til psykoanalyse.ad Notam Gyldendal as. Oslo. Norway 1999.

16. Strauss, A. C., \& Corbin, J. M. Basics of Qualitative Research: Second Edition: Techniques and Procedures for Developing Grounded Theory (2. utg.). Sage Publications, Inc. 1998.

17. Yin, R. K. Case Study Research: Design and Methods. (Fourth Edition). California. Sage Publications, Inc. 2008.

18. Lambert, M. J., Bergin, F. J., \& Garfield, S. L. Bergin and Garfield's handbook of psychotherapy and behavior change. New York: Wiley, 2004.

19. Duncan, B. L., Miller, S. D., Wampold, B. E., \& Hubble, M. A. The Heart and Soul of Change: Delivering What Works in Therapy (2. ed.). American Psychological Association. 2009.

20. Steinar K, Svend B. Learning the Craft of Qualitative Research Interviewing. Third Edition. SAGE Publications, Inc, 2015

21. Cade, B., \& O’Hanlon, B. A Brief Guide to Brief Therapy (1. utg.). W. W. Norton \& Company, 1993.

22. Bandler, R., \& MacDonald, W. An insiders Guide to Sub-Modalities. Metapublications. 1998.

23. Kringlen, E. Psykiatri. Oslo: Gyldendal akademisk. Oslo. Norway, 2011.

24. Lambert MJ \& et al. Enhancing psychotherapy outcome via providing feedback on Client progress: A Replication. Clinical psychology and psychotherapy 2002; 9, 91-103.

25. Ulvestad, A. K. Klienten - den glemte terapeut: brukerstyring i psykisk helsearbeid. Oslo: Gyldendal Akademisk. Norway, 2007.

26. Pickersgill M. 'Promising' therapies: neuroscience, clinical practice, and the treatment of psychopathy. Sociology of Health \& Illness Vol. 33 No. 32011 ISSN 0141-9889, pp. 448-464 doi: 10.1111/j.14679566.2010 .01286$.

27. APA. Diagnostic and statistical manual of mental disorders: DSM-IV. American Psychiatric Association. 2011.

28. Watzlawick P, Weakland J.H. Fisch R. Change: Principles of Problem Formation and Problem Resolution. Amazone, 1974

29. Anderson, H. Conversation, Language, And Possibilities: A Postmodern Approach To Therapy (1. ed.). Basic Books. New York 1997.

30. Damasio A. Følelsen av hva som skjer: Kroppens og emosjonenes betydning for bevisstheten. Pax: Oslo. Norway, 2001

31. Norcross, J. C. Dispelling the Dodo bird verdict and the exclusivity myths in psychotherapy. Psychotherapy: Theory, Research, Practice, Training, 32, 500-504. (1995). 